\title{
Economic Value and User Remuneration for EV Based Distribution Grid Services
}

\author{
Calearo, Lisa; Thingvad, Andreas; Ipsen, Hans Henrik; Marinelli, Mattia
}

Published in:

Proceedings of 2019 IEEE PES Innovative Smart Grid Technologies Europe

Link to article, DOI:

10.1109/ISGTEurope.2019.8905740

Publication date:

2020

Document Version

Peer reviewed version

Link back to DTU Orbit

Citation (APA):

Calearo, L., Thingvad, A., Ipsen, H. H., \& Marinelli, M. (2020). Economic Value and User Remuneration for EV Based Distribution Grid Services. In Proceedings of 2019 IEEE PES Innovative Smart Grid Technologies Europe IEEE. https://doi.org/10.1109/ISGTEurope.2019.8905740

\section{General rights}

Copyright and moral rights for the publications made accessible in the public portal are retained by the authors and/or other copyright owners and it is a condition of accessing publications that users recognise and abide by the legal requirements associated with these rights.

- Users may download and print one copy of any publication from the public portal for the purpose of private study or research.

- You may not further distribute the material or use it for any profit-making activity or commercial gain

- You may freely distribute the URL identifying the publication in the public portal 


\title{
Economic Value and User Remuneration for EV Based Distribution Grid Services
}

\author{
Lisa Calearo $^{1}$, Andreas Thingvad ${ }^{1}$, Hans Henrik Ipsen $^{2}$, and Mattia Marinelli ${ }^{1}$ \\ ${ }^{1}$ Department of Electrical Engineering, Technical University of Denmark, Risø Campus, Roskilde, Denmark \\ ${ }^{2}$ Bornholms Energi and Forsyning A/S. Bornholm, Denmark \\ \{lica, athing,matm\}@elektro.dtu.dk; hhi@beof.dk
}

\begin{abstract}
This paper describes a method to estimate the monetary remuneration for the $\mathrm{EV}$ user support in distribution grids. The economic expenses of the conservative reinforcement solution are used for developing the methodology which is first derived and afterwards applied to a piece of Danish distribution grid consisting of 127 customers. In the conservative scenario the DSO should invest approx. 388718 DKK (52000€) on new upgraded components. With EV support service the potential available money for the EV support remuneration is evaluated to be $187 \mathrm{DKK} /$ week (25€/week). Considering a customer with an average $E V$ load consumption, the annual remuneration would be 77 DKK $(10 €)$. It is concluded that, if the components are severely overloaded, for the DSO it is more cost effective to invest in components upgrade. Conversely if the components are barely overloaded or close to their limit, the $\mathrm{EV}$ user support can benefit both the DSO and the users.
\end{abstract}

Index Terms-Distribution grid, electric vehicles, loading issue, flexibility, user remuneration.

\section{INTRODUCTION}

Nowadays the electric vehicles (EVs) are catching on the transportation sector market. On the other hand their impact on the distribution power systems is difficult to predict, because of their dependency on user behaviour, penetration level, distribution grid characteristics etc. [1] - [3]. Even though the difficulties on the forecast of the EV charging characteristics, given the increasing penetration of EVs in the market, the DSOs aim to be prepared to high EV penetrations, defining technical- and economic- strategies to deal with the problems the EVs can cause. Large EV integration requires different components contributions: control systems and strategies, new markets actors, market signals, new regulations etc. [4]. In the literature various authors investigate the economic value of the EVs based on different control strategies [4] - [9]. Revenue estimates vary from few euros per year to thousands euros, depending on control strategies, markets, charging assumptions, etc.. In [4] the authors estimated a service remuneration for EV support between 16 and $51 € /$ year per customer, in [5] the price per $\mathrm{kWh}$ of ancillary service provision is around 1.4 DKK $(0.19 €)$, in [6] the net profit varies around 2000 USD/year (1764€/year) depending on the vehicle-togrid (V2G) considered market and in [9] between 1200 and

The work in this paper has been supported by the research projects ACES (EUDP grant nr: EUDP17-I-12499) and CAR (EU-Interreg grant nr: STHB.03.01.00-SE-S112/17)
2400 USD (1058-2116€) a year by participating in the US frequency regulation market. In [8], a net profit of $910 € / y e a r$ is found for the Danish frequency regulation market. Different values that strongly depend on the assumptions. For example in [4] the authors assumed a concurrent plug-in of all the vehicles at 18:00, in [8], [9] the vehicles are assumed to provide regulation services for 15 hours a day. In this paper, the authors aim at defining the value of the EVs and their monetary remuneration, when used as flexible active components for the distribution system network, based on real household consumption data and differentiated charging pattern scenarios. This paper analyses an alternative approach to the expensive reinforcement solution to loading issues. The analysis is applied to a Danish study case, previously investigated by the authors in [7], which could get heavily loaded during the simultaneous uncontrolled charging in the case of high EV penetrations.

This paper is organized as follows. In Section II a general overview of the current DSO solution to congestion issues is outlined. Section III discusses the economic assessment of DSO-based service from EVs. Section IV and V present the technical and economic characteristics of the tested study case. Section VII concludes the article with the main outcome results.

\section{CONSERVATIVE DSO APPROACH TO CONGESTION ISSUES}

The current DSO solution to congestion issues is the upgrade of the constrained components. Transformer and distribution cables are the components that can get overloaded during operation. The upgrade of a transformer consists in replacing the existing transformer with a larger one. The new transformer has to be established in the same place, and the substation infrastructure adaptation, such as space, ventilation, and connection are considered the same of the old transformer. It has to be highlighted that it may not be the case and additional construction works could be needed.

In the economic analysis the transformers differ from other network components due to the following reasons [10]:

- The capital expenditure (CAPEX) to operation and maintenance costs $(\mathrm{O} \& \mathrm{M})$ cost ratio is very large.

- No significant increase in failure rate with age have been observed until now, since failures tend to be of a 
random nature. Nevertheless, the increase of risk failures is classified from $0.5 \%$ when the transformer has less than 15 years, to $3 \%$ when the transformer has more than 50 years $(0.5 \%$ is excellent, $2 \%$ acceptable, $\geq 2 \%$ unacceptable) [10].

- There are no established criterion for technical lifetime estimation of the transformers.

Similarly to the transformer, upgrading the cables involves the expenses of the new cables and the replacement costs. In case of an upgrade, the new cable need a higher nominal current, which means larger cable section. Nevertheless the main cost comes from the replacement, which increases in urban and semi-urban distribution grids, where underground cables are mainly used.

In this paper the economic expenses for the upgrade of transformer and cables are based only on the CAPEX. The operating expense (OPEX) are assumed to be the same for old and new equipment.

\section{ECONOMIC ASSESSMENT OF DSO-BASED SERVICE FROM ELECTRIC VEHICLES}

In this section the EV service support is described as a new approach for solving congestion issues. The basic idea is that the DSO is allowed by the EV owners to decrease their active power consumption of the EVs when some components are about to be overloaded. In this way the components would not get overloaded and the DSO would not need to change/upgrade them. In the meantime the involved EVs would receive less power, a part of the energy consumption would be temporarily delayed and the charging time would consequently last longer. Without the EV users' consent this strategy would not be applicable. To get the users' acceptance a monetary remuneration is required, therefore the economic remuneration for the EV support is evaluated based on the cost of the component upgrade solution. In the rest of the manuscript the conservative solution to overloading issues, where the DSO invests in transformer and cables upgrading, is named "economic scenario 1 (ES1)". The proposed approach, where the DSO decides to postpone the components upgrade and adopt the EV support service is named "economic scenario 2 (ES2)". The ES1 and ES2 are graphically presented in Fig. 1. The lifetime of electrical components, such as transformer and cables, is generally considered to be 40 years [11], [12]. In ES1 the investment for the new components is made in year 0 , when the upgrade of the components is required. In ES2 the investment is delayed $x$ years, where $x$ is the remaining lifetime of the component. $x$ is function of the component age in year 0 and the amount of years the component is expected to work. In Fig. 1 it can be seen that, not only the first investment is delayed, but also the following ones. This means that, on the long-term the investment delay represents a saving for the DSO, which can invest the saved money on other purposes: in this case the EV user's support. Thus, the DSO savings are in ES2 the maximum amount of money that the DSO has available to pay for the EV support service. Considering the economic lifetime of the new components of 40 years, the money available for the EV support service $\left(M_{E V}\right)$ is the amount saved for the $x$ years as evaluated by Eq. 1:

$$
M_{E V}=\frac{C A P E X}{40} \cdot x
$$

It is important to have a good lifetime estimation of the components, because this prediction affects the evaluation of the available money that the DSO can use to pay for the EV support. The lifetime of transformer and cables usually varies between 30 and 50 years [11], [12], thus, with the same CAPEX but a longer lifetime, $M_{E V}$ would be lower, decreasing the available money that the DSO can use for the EV support payment.

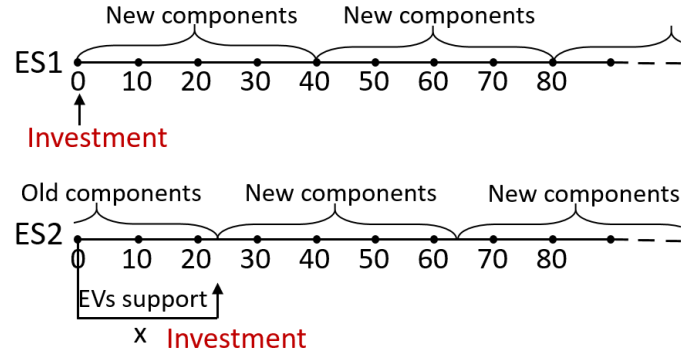

Fig. 1. ES1 and ES2 framework comparison.

\section{TECHNICAL CHARACTERIZATION}

\section{A. Distribution Grid Characteristics}

The methodology proposed in this paper has been applied to the grid in Fig. 2.

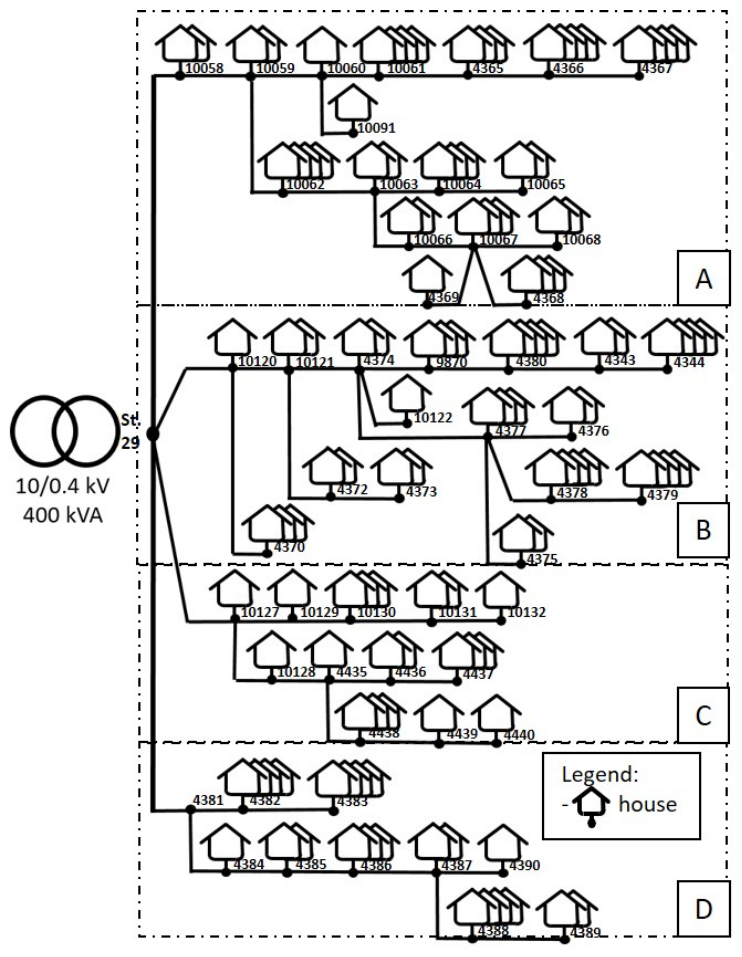

Fig. 2. Topology of simulated Tejn LV grid [7]. 
The grid has been analyzed by the authors in a previous work [7]. The model, simulated in DIgSILENT PowerFactory, consists of a radially run, semi-urban LV grid, based on a real network located in the Danish town of Tejn, Bornholm. The $\mathrm{LV}$ grid $(\mathrm{Un}=400 \mathrm{~V})$ is connected to the $\mathrm{MV}$ grid $(\mathrm{Un}=10 \mathrm{kV})$ through a 10/0.4 kV $400 \mathrm{kVA}$ distribution transformer and is supplied by under-ground cables. The grid consists of 4 feeders, with 127 users located as in Fig. 2. Similarly to previous Danish grid investigations [13], analyzing the data of week 10 from the Smart Grid Unit (SGU) meters present at the transformer St. 29, the grid is found to be unbalanced. Phase a is more loaded than b and c, so $40 \%$ of the measured three-phase load is set in phase a, 30\% in phase b and $30 \%$ in phase c. The analyzed week is the winter week 9 , from the 26th of February to the 4th of March 2018. The households electricity consumption is measured with the new smart meters installed under EU regulation and the total consumption can be seen in Fig. 3. The consumption of the considered week includes electric heating, meaning that the total consumption is actually higher than the average weekly consumption during the entire year. An inductive power factor of 0.96 is assumed. For more info about the grid characteristics refer to [7].

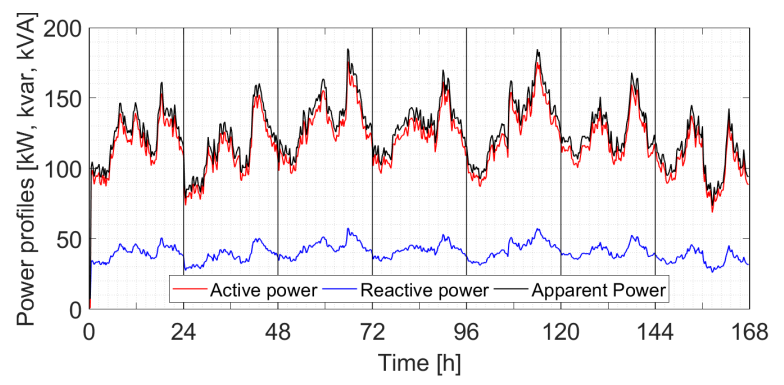

Fig. 3. Consumption profiles in the real Tejn LV grid week 9 2018, without EVs [7].

\section{B. Electric Vehicles Integration}

The EVs are included in the simulation under the assumption that each household owns one car, which for a $100 \%$ penetration means $127 \mathrm{EVs}$. The EV charging characteristics are dependent on daily distance driven, human range anxiety, etc. [7]. The EV charging patterns are derived in [7]. It is relevant to consider differentiated charging patterns to avoid overestimation of the loading profile. Nevertheless, considering a conservative scenario, the EVs plug-in at 16:00, 17:00, 18:00 or 19:00, coinciding with households' peak demand.

All EVs have a capacity of $40 \mathrm{kWh}$ Lithium-ion battery and they are three-phase units with a maximum charging rate of $11.1 \mathrm{~kW}(16 \mathrm{~A}, 400 \mathrm{~V})$. The charging rate profile is constant during the charging time until $100 \%$ State of Charge (SOC) is reached, though in reality it would start to decrease after $95 \%$ SOC.

\section{Technical results}

Fig. 4 summarizes the voltage of the most critical terminal on the left and the transformer and cable loading on the right [7].

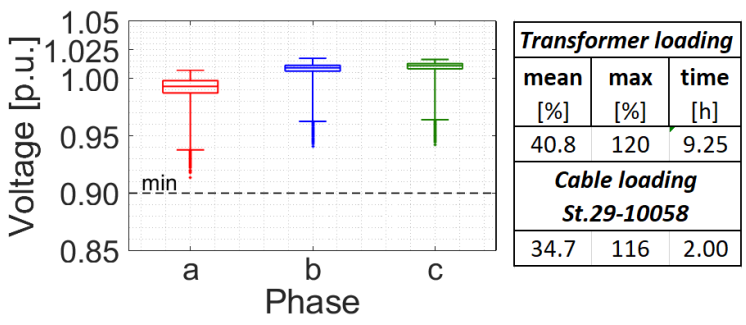

Fig. 4. The figure shows: on the left the phase-to-neutral voltage for junction 4379 ; on the right the comparison mean, max and time duration of transformer and cable loading during one week [7].

\section{ECONOMIC CHARACTERIZATION}

The economic scenarios, ES1 and ES2, previously analyzed are here applied to the case in Tejn, where the $100 \% \mathrm{EV}$ penetration causes the transformer overloading for approx. $9.25 \mathrm{~h}$ and the cables St-10058 and 10058-10059 overloading for $2 \mathrm{~h}$ and $25 \mathrm{~min}$, respectively.

First and foremost the techno-economic characterization of the upgraded transformer and cables, which should be used in ES1, are provided in Table I and II respectively. The total investment would be 388718 DKK (52000€), sum of the CAPEX of transformer and cables.

TABLE I

DEFINED PARAMETERS AND PRICE OF THE MV/LV TRANSFORMER FOR THE PROPOSED GRID REINFORCEMENT SOLUTION. THE ECONOMIC INPUTS HAVE BEEN OBTAINED FROM [4], [12].

\begin{tabular}{cc|cc}
\hline \multicolumn{4}{c}{ MV/LV Transformer characteristics } \\
\hline \hline Technology & $3 \mathrm{PH}$ & Lifetime & 40 years \\
\hline Rated power & $630 \mathrm{kVA}$ & CAPEX & 319500 DKK $(42800 €)$ \\
\hline Nominal frequency & $50 \mathrm{~Hz}$ & & OPEX input \\
\hline Rated voltage, HV & $10 \mathrm{kV}$ & O\&M Cost Rate & $3.50 \%$ of CAPEX/year \\
\hline Rated voltage, LV & $0.4 \mathrm{kV}$ & O\&M Cost & 11183 DKK/year $(1498 € /$ year) \\
\hline Connection & Dyn11 & OPEX & 11183 DKK/year $(1498 € /$ year) \\
\hline \hline
\end{tabular}

TABLE II

DEFINED PARAMETERS AND PRICES OF THE CABLE Al PEX 4X240 MM, FOR THE PROPOSED GRID REINFORCEMENT SOLUTION. THE ECONOMIC INPUTS HAVE BEEN OBTAINED FROM [12].

\begin{tabular}{cc|cc}
\hline \multicolumn{4}{c}{ Cable characteristics } \\
\hline \hline Technology & $3 \mathrm{PH}$ & Lifetime & 40 years \\
\hline Cross section & $240 \mathrm{~mm}^{2}$ & Cost per meter* & 653 DKK $(88 €)$ \\
\hline Rated voltage & $0.4 \mathrm{kV}$ & CAPEX** & 69218 DKK $(9273 €)$ \\
\hline Rated current & $400 \mathrm{~A}$ (in ground) & & OPEX input \\
\hline Positive Resistance & $0.126 \Omega / \mathrm{km}$ & O\&M Cost Rate & $3.50 \%$ of CAPEX/year \\
\hline Positive Reactance & $0.069 \Omega / \mathrm{km}$ & O\&M Cost & 2423 DKK/year $(325 € /$ year) \\
\hline Lenght cable St-10058 & $50 \mathrm{~m}$ & OPEX & 2423 DKK/year $(325 € /$ year) \\
Lenght cable $10058-10059$ & $56 \mathrm{~m}$ & & \\
\hline \hline
\end{tabular}

*Cost per meter of the cable, AL PEX 4x240 mm, including material and wages.

**Total CAPEX for the replacement of the two cables St-10058 and 10058-10059.

Transformer and cables present in Tejn are 40 years old [7], but are in good conditions, and the DSO could use them for at least 10 more years. For this reason the remaining lifetime $x$ of Eq. 1 is assumed to be of 10 years. In Fig. 5 the two scenarios are demonstrated for the present case. Year 0 is considered as the present year, but assuming 100\% 
EV penetration. Considering the same electric consumption for all the weeks of the 10 years, the money available for the EV support service for 10 years is evaluated using Eq. 2.

$$
M_{E V}=\frac{388718 D K K}{40 y} \cdot 10 y=97180 D K K
$$

The 10 years, one year and one week savings are evaluated and provided in Table III.

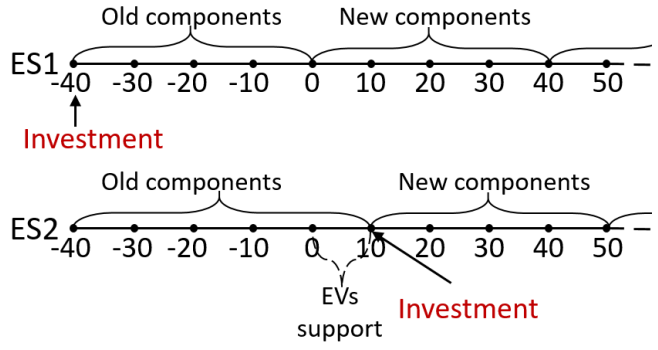

Fig. 5. ES1 and ES2 framework comparison for Tejn study case.

The maximum amount of money that the DSO would save per week in ES2 is 186.9 DKK $(25 €)$. This amount gives an idea of the economic value of the EV support service, but it does not say how these money should be split between the users. For this reason, in the following analysis the authors describe a methodology to define the users' contribution and their remuneration.

TABLE III

ES2: MAXIMUM MONEY AVAILABLE FOR EV SUPPORT SERVICE PAYMENT.

\begin{tabular}{lc}
\hline \multicolumn{2}{c}{ ES2 } \\
\hline \hline Money available for 10 years & 97180 DKK $(13019 €)$ \\
\hline Money available per year & 9718.0 DKK $(1302 €)$ \\
\hline Money available per week & 186.9 DKK $(25 €)$ \\
\hline \hline
\end{tabular}

\section{A. Users' remuneration}

The transformer loading was provided in Fig. 4. The consumption above the $400 \mathrm{kVA}$ of the transformer is the energy ${ }^{1}$ that the DSO should move to avoid the overloading of the transformer. Neglecting the losses of transformer and cables, the energy is assumed to be completely provided by the EVs. During the support service the EV consumption is reduced, therefore the total charging time will last longer, until the EVs are fully charged.

The loading of the cables is provided as well in Fig. 4. The cables are overloaded when the transformer is already overloaded, as shown in Fig. 6 with a detailed overlap of transformer and cables loading from 12:00 to 24:00 on Saturday. If the support service is equally distributed between the EVs in the grid, it can be assumed that the moved energy, area between the apparent power of the transformer and the limit line of $400 \mathrm{kVA}$ shown, will also reduce the cable loading. The

\footnotetext{
${ }^{1}$ For simplicity the energy to move (in $\mathrm{kWh}$ ) is derived from the apparent power in $\mathrm{kVA}$. This is possible because of the small share of reactive power
}

energy to be moved during the entire week, due to overloading of the transformer, is quantified to be of $393 \mathrm{kWh}$.

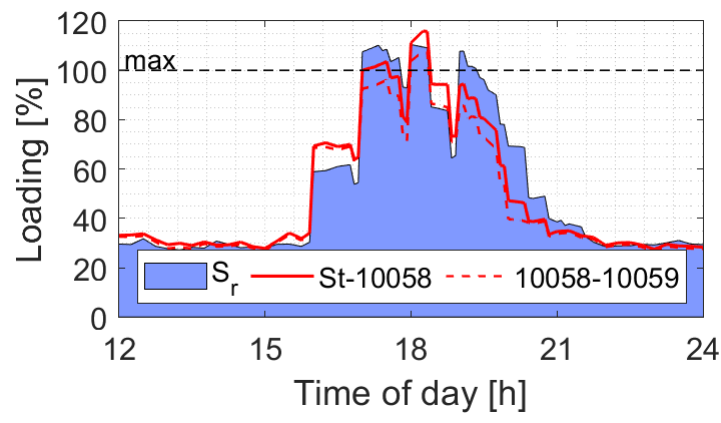

Fig. 6. Transformer $\left(S_{r}\right)$ and cables (St-10058, 10058-10059) loading comparison from 12:00 to 24:00 on Saturday.

Considering the potential saving from Table III and the moved energy per week, the ratio between the two gives the maximum payment per week of $0.48 \mathrm{DKK} / \mathrm{kWh}$ that the DSO would have available for the EV support service.

\section{RESULTS}

The lower is the energy to move during one week, the higher is the amount of money per $\mathrm{kWh}$ that can be used by the DSO for paying back the moved energy. From the EV users' perspective, this means that the EV support is paid less $\mathrm{DKK} / \mathrm{kWh}$ when more support is provided. Considering an equal distribution of the moved energy between the charging EVs, the moved energy per EV owner is $3.09 \mathrm{kWh} /$ week. Thus the savings for an average EV user ${ }^{2}$ are found to be $1.48 \mathrm{DKK}$ $(0.20 €)$ per week, and 77.0 DKK $(10 €)$ per year. From the point of view of the DSO, the EV support in ES2 is used as alternative solution to components upgrade in ES1. The new components would represent a huge investment for the $\mathrm{DSO}$, and as consequence the investment has to be preferable to other, if there are, alternatives. In this study case the transformer is overloaded for some hours in a week, but it has to be noticed that the household consumption during the year is not always high as during this week. In [7] it has been shown that the considered week is a highly loaded week, due to the presence of electric heating and the low outside temperatures. Having limited overloading, the EV support service becomes much more interesting for the DSO, as it would need to move a small amount of energy to avoid congestion. Since the domestic electricity consumption is higher in the winter, the DSO could buy the EV support service for a few months per year for a higher compensation per $\mathrm{kWh}$.For example, buying the service only for three months the DSO could payback the EV support with $2.06 \mathrm{DKK} / \mathrm{kWh}(0.276 € / \mathrm{kWh})$. The abovedescribed case is summarized in Table IV:

\footnotetext{
${ }^{2}$ This approximation is made to give an average value of payment per customer, even though the EVs charging patterns are different and there would be some EV users earning more and some less.
} 
TABLE IV

ES2: EV SUPPORT SERVICE FOR THREE MONTHS PER YEAR.

\begin{tabular}{lc}
\hline \multicolumn{2}{c}{ ES2 } \\
\hline \hline Money available for 10 years & 97180 DKK $(13019 €)$ \\
\hline Money available per 3 months (12 weeks) & 9718.0 DKK $(1302 €)$ \\
\hline Money available per week & 810 DKK $(109 €)$ \\
\hline Moved energy during one week & $393 \mathrm{kWh}$ \\
\hline Maximum payment per kWh & 2.06 DKK $(0.276 €)$ \\
\hline \hline
\end{tabular}

The remuneration per $\mathrm{kWh}$ is higher than in the previous case, nevertheless the yearly remuneration for an average EV user would be the same (77.0 DKK/year). This is due to the fact that the available amount of money for the service remuneration is the same, and it would only be differently distributed over the year.

When looking at $100 \% \mathrm{EV}$ penetration, not expected to happen before the 2050 [14], the electricity consumption growth has also to be considered. Indeed the investment delay can also be seen as an opportunity for the DSO to determine the most appropriate size of the overloaded components. For instance, if during the years the EV support service is proved to be a balanced solution for DSO, power system and users, the DSO could also decide to change the old components with new of the same characteristics. For the example in Tejn, the transformer could be changed after 10 years with a similar one of $400 \mathrm{kVA}$ and the cables with new ones with same characteristics. Considering that the main price component of the new cables comes from the replacement, the cost of the new cables can be considered the same as the one seen in Table II. Contrarily, the investment for the transformer of 400 $\mathrm{kVA}$ is lower than the investment for a new one with 630 $\mathrm{kVA}$. The difference between the two investments is of 116643 DKK (15626€) and it could be considered for the EV support service remuneration [7]. It has to be mentioned that, even though there are no written rules it is common practice to consider a maximum loading factor for the transformers equal to $70 \%$. In this sense, the considerations made in the paper take the maximum load as $100 \%$, but if the $70 \%$ rule is enforced, a lower EV penetration scenario would be problematic with consequences on the transformer size decisions [15].

\section{CONCLUSION}

In this manuscript the use of the EVs as service providers was investigated in attempt to avoid overloading issues in the power system. The techno-economic value of the service was derived from the point of view of the power system, aggregator and user. The traditional DSO solution to congestion issues was found to be preferable when the components are highly overloaded. On the contrary the EV support service is more cost-effective when the overloading periods are short and spread out in time. Nevertheless, the EV support service precludes the acceptance of the users to cooperate with the DSO for the grid management. The EV users accept the reduction of the EV electricity consumption during the charging time, to avoid overloading of grid components, in return of a monetary remuneration. The remuneration is evaluated based on the savings that the DSO would have if using the EV support service instead of upgrading the components. The investigation of a Danish low voltage grid showed that the conservative solution would require an initial investment of 388718 DKK (52000€) for upgrading the transformer and two cables. Based on this, it was found that the EV support service could be paid $0.48 \mathrm{DKK} / \mathrm{kWh}(0.064 € / \mathrm{kWh})$, and an average customer could earn approx. 77.0 DKK (10€) per year. It can be concluded that with severe overloading the conservative solution is preferable due to the associated uncertainty when procuring the service with EVs. Whereas with limited overloading periods the EV support service is more cost-effective. Moreover, the overloading is mostly expected during winter, thus the DSO could benefit from the EVs for fewer months with the possibility of higher remuneration per $\mathrm{kWh}$ of support. The EV support generates benefit for the society, because it is procured and rewarded only when needed, whereas the grid reinforcement is a permanent characterization.

\section{REFERENCES}

[1] MS Elnozahy, MMA Salama. A comprehensive study of the impacts of PHEVs on residential distribution networks. IEEE Trans Sustain Energy 2014;5:332-42. doi:10.1109/TSTE.2013.2284573

[2] PY Kong, GK Karagiannidis. Charging Schemes for Plug-In Hybrid Electric Vehicles in Smart Grid: A Survey. IEEE Access 2016;PP. doi:10.1016/j.jallcom.2014.03.093.

[3] K. Knezović, M. Marinelli, A. Zecchino, P. B. Andersen, and C. Traeholt. Supporting involvement of electric vehicles in distribution grids: Lowering the barriers for a proactive integration. Energy, vol. 134, pp. 458-468, 2017.

[4] A. Gadea, M. Marinelli, and A. Zecchino, "A market framework for enabling electric vehicles flexibility procurement at the distribution level considering grid constraints," 20th Power Syst. Comput. Conf. PSCC 2018, 2018.

[5] E. Larsen, D. K. Chandrashekhara, J. Østergård, "Electric Vehicles for Improved Operation of Power Systems with high wind power penetration,’ IEEE Energy2030 Atlanta, GA USA 17-18 November, 2008.

[6] W. Kempton and J. Tomić, "Vehicle-to-grid power fundamentals: Calculating capacity and net revenue," J. Power Sources, vol. 144, no. 1, pp. 268-279, 2005.

[7] L. Calearo, "Flexibility procurement by EVs in a Danish active distribution network: Study cases from the island of Bornholm," M.Sc. thesis in Sustainable Energy, DTU, Jun 2018 (supervisors: M. Marinelli, A. Thingvad, H. H. Ipsen (BEOF) and Roberto Turri (Univ. of Padova)).

[8] A. Thingvad, C. Ziras, and M. Marinelli, "Economic value of electric vehicle reserve provision in the nordic countries under driving requirements and charger losses," Journal of Energy Storage, vol. 21, pp. 826 - 834, 2019.

[9] S. Kamboj, W. Kempton, and K. Decker, "Deploying power gridintegrated electric vehicles as a multi-agent system," 10th Int. Conf. ..., no. Aamas, pp. 13-20, 2011.

[10] CIGRE Working Group A2.20, “Guide on Economics of Transformer Management,” no. June, p. 68, 2004.

[11] J. Paul, W. Zhongdong, Z. Qi, and I. Taufiq, "End-of-life Modelling for Power Transformers in Aged Power System Networks," CIGRE 2009 Reg. Conf., no. August, p. reference, 2009.

[12] Danish Energy Agency, "Technology Data for Energy Transport," no. December, 2017.

[13] K. Knezovic, M. Marinelli M. Phase-wise enhanced voltage support from electric vehicles in a Danish low-voltage distribution grid. Electr Power Syst Res 2016;140:274-83. doi:10.1016/j.epsr.2016.06.015.

[14] Nordic Energy Research, "Sustainable shift: Nordic energy systems towards 2050," 2016.

[15] ipower consortium. Development of a dso-market on flexibility services. Report, 2013. 